\title{
Algumas observações sobre a babesiose dos cães no Rio de Janeiro
}

\author{
por \\ W. Lobato Paraense e Yderzio Luiz Vianna
}

(Com 2 tabelas)

Durante os meses de março a maio de 1948 estivemos fazendo um rápido inquérito sôbre a incidência da babesiose dos cães na cidade do Rio de Janeiro. Para isto examinamos 100 cães adultos chegados ao Biotério do Instituto Oswaldo Cruz durante aquele período, enviados pelo Departamento de Limpesa Urbana da Prefeitura do Distrito Federal. São animais apanhados nas ruas de todos os bairros, principalmente da zona norte, de modo que os dados obtidos permitem uma avaliação aproximada da incidência da infecção nesta cidade.

Além dos resultados desse inquérito tivemos oportunidade de obter algumas informações de ordem clínica e parasitológica, as quais são também referidas na presente nota.

\section{MATERIAL E MÉTODOS}

Os cães vistos neste inquérito não foram selecionados, tendo sido examinados na ordem de chegada ao Biotério até ser completado o número de 100 .

A pesquisa de babésias foi feita em preparados de sangue distendido, corados pelo método de Leishman, sendo examinados 100 campos em cada preparado. O exame foi feito em trechos nos quais as hemácias estavam distribuidas regularmente e em número aproximado de 150 por campo microscóp:co.

Os animais foram examinados durante um periodo de 4 dias consecutivos, contados a partir do dia da chegada ao Biotério.

Vários dos cães observados foram necropsiados, sendo feitos esfregaços dos seguintes órgãos: cérebro, pulmão, fígado, baço, rim, medula óssea e gânglios linfáticos. As preparações, depois de fixadas em álcool metílico, foram coradas pelo método de Giemsa e examinadas para protozoários. Frag- 
mentos desses e de outros órgãos foram tratados por fixadores histológicos para estudos ulteriores, cujo resultado não constará deste trabalho.

Das vísceras retiradas de todos os animais necropsiados foram sempre conservados fragmentos à temperatura de congelação, enquanto se aguardava o exame dos respectivos esfregaços. Em dois destes casos foram encontradas certas formas parasitárias cuja natureza foi investigada mediante inoculação de polpa de baço destes dois animais em cães, cobaias, camondongos e pombos. Nos casos referidos a polpa esplênica era muito difluente, sendo fàcilmente emulsionada em água fisiológica e inoculada por via subcutânea.

Estes animais inoculados também foram necropsiados, sendo examinados esfregaços de cérebro, pulmão, fígado, baço, rim, medula óssea e gânglios linfáticos. Dos pombos foram examinados cérebro, pulmão, fígado, baço e rim.

\section{RESULTADOS}

\section{INCIDÊNCIA DA INFECÇÃO}

$\mathrm{Na}$ tabela 1 estão reunidos os resultados da pesquisa de babésias no sangue dos 100 cães observados neste inquérito, entre os quais foram encontrados 14 positivos.

O número de parasitos vistos em cada exame indica a fraca intensidade da infecção em quase todos os animais positivos, como é a regra na babesiose crônica. Sendo as babésias, nestes casos crônicos, muito raras no sangue periférico, a probabilidade do encontro de parasitos aumenta quando se fazem pesquisas repetidas durante muitos dias. Não prolongamos os exames além de 4 dias porque os animais vão sendo fornecidos aos laboratórios do Instituto, tornando-se cada dia menos numerosos, e também porque alguns daqueles que não estão infectados podem adquirir a babesiose no próprio Biotério, onde sempre são introduzidos carrapatos. O prazo de 4 dias sendo inferior ao período habitual da incubação parasitêmica, ficam assim excluidos os casos de infecção eventualmente adquirida no local.

O índice de morbilidade assim obtido (14\%) está certamente muito abaixo da realidade, pois é sabido que na babesiose crônica pode haver uma longa série de dias em que o sangue periférico mantém-se negativo, e por outro lado a grande difusão, entre os cães de rua, do Rhipicephalus sanguineus, transmissor desta babesiose no Rio de Janeiro (Regendanz \& Muniz, 1936), indica a existência de uma intensa e permanente atividade de transmissão. 
Dos 14 cães encontrados positivos durante este inquérito destacamos 7 para observação mais detalhada. Estes animais, somados a 8 que já haviam sido observados nos meses anteriores ao inquérito, perfazem o total de 15 cães com infecção natural que acompanhamos até à necrópsia, sendo que 11 dentre eles tiveram morte espontânea e os 4 restantes foram sacrificados.

\section{ASPECTO CLÍNICO DA BABESIOSE}

Talvez pelo fato de termos observado apenas cães adultos, os casos com infecção natural por nós verificados pertenciam todos à chamada forma benigna da babesiose. Apenas uma vez constatámos icterícia aliás pouco intensa.

Coincidindo com o aparecimento de parasitos na circulação periférica observa-se maior ou menor elevação térmica, normalizando-se a temperatura ao desaparecerem as babésias. Durante estes surtos de pirexia os animais ficam em estado de prostração mais ou menos acentuada, às vezes traduzindose apenas por certa indiferença ante os estímulos exteriores.

Nenhuma vez encontrámos a chamada forma hemorrágica, seja cutânea ou visceral. Tampouco vimos as características hemorragias do pavilhão da orelha, das quais a doença tira a sua denominação indígena de "nambiuvú" (orelha que sangra).

Neste número relativamente pequeno de cães observados tivemos a impressão de que a morte, nos casos em que ela foi espontânea, foi causada por doença intercorrente.

Apenas os dois cães muito jovens que inoculámos com polpa esplênica 2 dos quais nos ocuparemos mais adiante apresentaram sintomatologia mais nitida, morrendo em poucos dias com intensa parasitemia, acentuada tinta ictérica e forte anemia perceptivel macroscopicamente.

\section{ASPECTO MORFOLÓGICO DOS PARASITOS}

Observando a morfologia dos parasitos encontrados no sangue não foi possivel descobrir diferenças entre eles e aqueles descritos na infecção provocada pela Babesia canis.

Como veremos em seguida, certos parasitos viscerais encontrados em três casos, cuja morfoíogia apresentava semelhanças com as formas que Carini \& Maciel (1914) descreveram como pertencentes ao ciclo da babésia nos tecidos dos órgãos internos, apresentaram fortes indícios de serem toxoplasmas. 
Por estes motivos não nos sentimos autorizados a tratar o parasito por nós observado nos glóbulos vermelhos como diferente de Babesia canis, até que estudos ulteriores possam, como esperamos, esclarecer esta questão.

\section{AS FORMAS SEMELHANTES A TOXOPI.ASMAS}

Antes de iniciarmos o inquérito a que nos estamos referindo, tivemos oportunidade de observar alguns casos de babesiose em cães chegados ao Biotério do Instituto. Estes casos não estão catalogados entre os 100 animais constantes da tabela 1 .

O primeiro dentre eles foi encontrado positivo ao exame de sangue, com raras babésias, no dia 23-2-48. A infecção evoluiu discretamente, sem sintomatologia apreciável, mostrando-se o sangue ora positivo, ora negativo. Este animal morreu no dia 4-5-48, tendo permanecido negativo durante os 6 últimos dias de vida. Nos esfregaços e cortes dos órgãos foram encontrados parasitos muito semelhantes a toxoplasmas, os quais eram extremamente abundantes no baço e no fígado.

Infelizmente esta constatação foi feita no dia seguinte à necrópsia, quando já tinha sido desprezado o material não fixado.

Os parasitos referidos apresentavam aspectos muito parecidos àqueles que descreveram Carini \& Maciel (1914) como formas esquizogônicas da babésia nos tecidos, levando estes autores a crearem o novo gênero Rangelia e para ele transferirem o Piroplasma vitalii Pestana, 1910.

Ficámos então de sobreaviso para a eventualidade de reencontrarmos as referidas formas. Daí em diante passámos a retirar fragmentos dos órgãos a serem examinados, os quais eram conservados na geladeira para serem utilizados em caso de necessidade.

Assim, nas 14 necrópsias que depois fizemos, encontrámos mais duas vezes as referidas formas parasitárias. Em ambos estes casos os parasitos eram mais abundantes no baço e no fígado. Com emulsão da polpa ésplênica inoculámos vários animais, com os resultados que passamos a enumerar e que se acham resumidos na tabela 2 .

\section{Cão $n .^{\circ} 16$}

Como sé vê na tabela 1 , este animal apresentou 130 parasitos em 100 campos no $4 .^{\circ}$ dia de observação. Daí por diante a intensidade da parasitenıia foi sempre muito fraca. No dia da morte foram vistos 4 parasitos em 100 
TABELA I

RESULTADO DA PESQUISA DE BABÉSIAS NO SANGUE DE 100 CÃFS DE RUA DO RIO DE JANEIRO OBSERVADOS DURANTE 4 DIAS CONSECUTIVOS

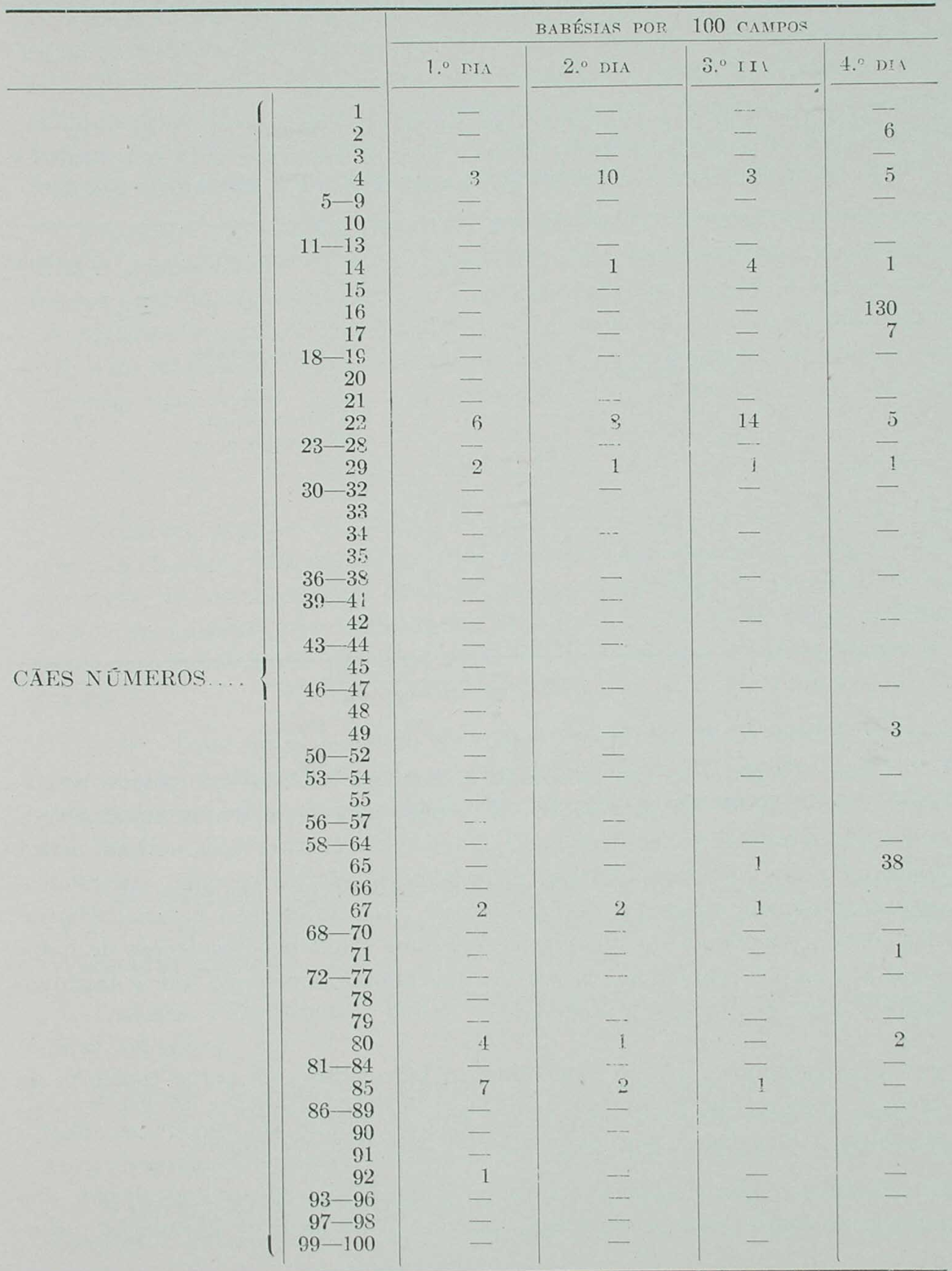


cámpos. Nos últimos dias de vida este cão apresentou diarréia. Constatada a presença de abundantes formas semelhantes a toxoplasmas, foi feita inoculação de polpa esplênica em 1 cão de 2 meses de idade, 10 camondongos, 3 cobaias e 3 pombos.

TABELA 2

RESULTADOS DAS INOCLLAÇÕES DE BAÇO DOS CÃES 16 E 49, COM ABUNDANTES FORMAS SEMELHANTES A TOXOPLASMAS, E DAS SUBINOCULAÇÕES DE ÓRGÃOS DE ANIMAIS INOCUI.ADOS COM BAÇO DO CÃO 16

\begin{tabular}{|c|c|c|c|c|}
\hline CÃO N. & INOCULAÇÕES & RESULTADO & SUBINOCULASÕES & RESULTADO \\
\hline 16 & $\begin{array}{c}1 \text { cão } \\
10 \text { camondongos } \\
2 \text { cobaias } \\
1 \text { cobaia } \\
3 \text { pombos }\end{array}$ & $\bar{E}$ & $\begin{array}{l}10 \text { camondongos } \\
7 \text { camondongos } \\
30 \text { camondongos }\end{array}$ & $\begin{array}{r}7+ \\
?\end{array}$ \\
\hline 49 & $\begin{array}{c}1 \text { cão } \\
7 \text { camondongos } \\
3 \text { cobaias } \\
3 \text { pombos }\end{array}$ & $\overline{-} \overline{-}$ & & \\
\hline - & TIVO & $+\mathrm{PC}$ & & \\
\hline
\end{tabular}

Cão. O pequeno cão inoculado apresentou babésias no sangue periférico 7 dias depois da inoculação. A parasitemia incrementou rapidamente, morrendo o animal 4 dias depois. O exame cadavérico revelou anemia, ascite, hipertrofia dos gânglios linfáticos e um abcesso séptico rompido espontaneamente, localizado no ponto de inoculação. Nos órgãos não foram encontradas formas semelhantes a toxoplasmas. Foram feitas subinoculações de polpa esplênica em 10 camondongos, por via subcutânea, morrendo todos negativos entre 5 e 68 dias após a inoculação.

Camondongos. Os 10 camondongos inoculados com polpa esplênica do cão n. 16 morreram todos com septicemia bacteriana entre o $3 .^{\circ}$ e o $7 .^{\circ}$ dias seguintes à inoculação, sem apresentarem parasitos nos órgãos.

Cobaias. Das 3 cobaias morreram 2 no $3 .^{\circ}$ dia após a inoculação, com intenso processo inflamatório agudo, provocado no local da inoculação e pro- 
pagado pelo tecido subcutâneo da parede abdominal. Nos órgãos foram en contradas bactérias fagocitadas em grande quantidade e nenhum protozoário. A terceira cobaia apresentou convulsões no $12 .^{\circ}$ dia após a inoculação, sendo então sacrificada. Havia um abcesso séptico, rompido espontaneamente, no local da inoculação. Nos órgãos não foram encontrados protozoários. Com polpa cerebral desta cobaia foram subinoculados por via subcutânea 7 camondongos, que morreram entre 11 e 13 dias depois, todos eles apresentando formas semelhantes a toxoplasmas, principalmente no pulmão e no cérebro.

Pombos. Os pombos resistiram aos efeitos da inoculação, sendo sacrificados depois de 45, 51 e 81 dias. Em nenhum deles foram encontradas formas semelhantes a toxoplasmas nos esfregaços dos órgãos. Com triturado de cérebro e fígado de cada pombo foram inoculados lotes de 10 camondongos, num total de 30 destes animais, os quais ainda permanecem vivos e sem sintomas aparentes.

\section{Cão n. 49}

Apareceu positivo no $4 .^{\circ}$ exame (tabela 1 ), apresentando parasitos por mais alguns dias. Morreu no dia 14-6-48. sendo encontradas no sangue 1 babésia em 100 campos e nas vísceras formas semelhantes a toxoplasmas em grande abundância, principalmente no baço e no fígado. Com polpa esplênica foram inoculados 1 cão de cerca de 2 meses, 3 cobaias, 7 camondongos e 3 pombos.

Cão. Apresentou babésias no sangue 6 dias depois da inoculação, morrendo 5 dias mais tarde com forte parasitemia, anemia e hipertrofia dos gânglios linfáticos. Não foram encontradas formas semelhantes a toxoplasmas nos órgãos.

Camondongos. Morreram 5 entre o $7 .^{\circ}$ e o $15 .^{\circ}$ dias após a inoculação e 1 no $60 .^{\circ}$ dia. O último foi sacrificado no $66 .^{\circ}$ dia. Em nenhum deles foram encontrados parasitos.

Cobaias. Morreram 2 no $10 .^{\circ}$ dia e a $3 .^{a}$ no $25 .^{\circ}$ dia após a inoculação, todas negativas.

Pombos. Morreram no $199^{\circ}, 200^{\circ}$ e $22 .^{\circ}$ dias após a inoculação. Em todos foi encontrada grande quantidade de formas semelhantes a toxoplasmas nos esfregaço de fígado, e em menor número no baço, pulmão, cérebro e rim.

A morfologia dos parasitos encontrados nos órgãos internos dos três cães referidos e o aparecimento de formas análogas em vários dos animais ino- 
culados com material proveniente de dois daqueles cães são indícios sugestivos de que nos três casos assinalados havia concomitância de toxoplasmose. Entretanto o número de casos observados é ainda muito pequeno e os resultados das inoculações foram um tanto discordantes para permitirem conclusões definitivas. Não está afastada a possibilidade de prévia infecção espontânea por toxoplasmas na cobaia e nos pombos positivos. De qualquer modo, este é um assunto no qual a última palavra só deverá ser dita depois de experiências mais completas.

\section{UM CASO DE BABESIOSE ESPONTANEA EM CÃO SELVAGEM}

Antes de concluir a presente nota queremos assinalar o encontro de um caso de babesiose no Cerdocyon thous, vulgarmente chamado "cachorro do mato". Um exemplar desta espécie foi trazido ao Biotério do Instituto, morrendo 5 dias depois com parasitemia muito intensa. Este caso foi um achado de necrópsia. A morte, que ocorreu no dia 19-6 48, só foi constatada cerca de 36 horas depois, achando-se o cadáver em decomposição adiantada. Os parasitos eram numerosíssimos no sangue dos órgãos internos, principalmente no rim. A bexiga estava cheia de líquido sanguinolento. Havia também intensa icterícia .

Não foi possivel apurar qualquer dado pregresso a respeito deste animal. Podemos apenas afirmar que ele adquiriu a infecção antes de chegar ao Biotério, em vista de ser o prazo de 5 dias inferior ao período normal da incubação parasitêmica, sem levar em conta o tempo necessário ao incremento da infecção até o nível letal.

\section{CONCLUSÕES}

1. Entre 100 cães de rua da cidade do Rio de Janeiro, examinados em março, abril e maio de 1948, foram encontrados 14 portadores de babesiose crônica.

2. Em 15 cães atacados de babesiose crônica e observados até à necrópsia foram verificados os seguintes sintomas clínicos: febre coincidindo com o aparecimento de parasitos na circulação periférica; icterícia pouco intensa em um caso apenas; ausencia de hemorragias de qualquer natureza.

3. A morfologia dos parasitos não permite distinguí-los de Babesia canis.

4. Em 3 animais foram encontrados parasitos viscerais com morfologia de toxoplasmas, extremamente abundantes no baço e no fígado e menos numerosos em outros órgãos. Foram feitas inoculações de polpa esplênica de 2 destes cães em cobaias, camondongos, pombos e cães jovens, com résultados 
que sugerem a existência de infecção mixta por babésias e toxoplasmas nos 3 cães referidos.

5. E' assinalado o encontro de um caso de babésiose espontânea muito virulenta em "cachorro do mato" (Cerdocyon thcus), com intensa icterícia e hemoglobinuria, provocando a morte do animal.

\section{CONCLUSIONS}

1. A rapid survey among 100 street dogs in the city of Rio de Janeiro showed that 14 of them were infected with Babesia.

2. In 15 dogs chronically infected and under observation until death ensued the following clinical symptoms were found: fever coinciding with the appearance of parasites in the peripheral blood; slightly intense jaundice in only one case; absence of any hemorrhagic manifestations.

3. The parasites are morphologically, undistinguishable from Babesia canis .

4. In 3 dogs visceral Toxoplasma-like parasites were found to be very abundant in the spleen and liver, and less numerous in the other organs. The result of inoculations of splenic juice from 2 of these dogs into guinea pigs, mice, pigeons and puppies suggest the coincidence of mixed (babesia-toxoplasma) infections in the 3 dogs mentioned above.

5. A case of highly virulent spontaneous babesiasis was observed in an adult wild dog (Cerdocycn thous) which died with severe jaundice and hemoglobinuria .

\section{REFERENCIAS}

Carini, A. E J. Maciel

1914. Sobre a molestia dos cães, chamada Nambi-Uvú e o seu parasita (Rangelia vitalii). Ann. Paul. Med. Cir. 3 (3) : 65-71.

Regendanz, P. E J. Muniz

1936. O Rhipicephalus sanguineus como transmissor da Piroplasmose canina no Brasil. Mem. Inst. Osw. Cruz 31 (1) : 81-84. 